\title{
Home visits
}

Published at www.cmaj.ca on Sept. 27

A $\mathrm{s}$ a pediatric resident on a new social pediatrics elective, I expected to meet families who lived in complex and challenging circumstances.

I certainly did. In fact, the experience of visiting three families with various health care professionals and seeing first hand the physical dangers and deprivation of the environment they call "home" transformed my understanding of the impact of housing on health.

\section{The teenage mother}

The teenager delivered her first child seven days ago. The hallway to the highrise apartment where she lives with her parents, sister and nieces smells of rot. The windows are open and the towels that must cover them at night are pulled back. The room is hot and stagnant. We have to shout over the sounds of the fans, the TV, the traffic and a mechanical baby rocker that swings wildly back and forth.

There is nowhere to sit as every surface is covered with the family's belongings: cats, swings, rockers, bouncers. There is enough furniture to fill a room twice the size, but their previous place was flooded two months ago and this is where they are staying.

It is difficult to imagine where this baby will have the physical space to crawl and walk, or even a bit of space where it might be quiet.

\section{The basement apartment}

Behind a strip mall of take-away restaurants and odd shops, a young mother squats on the ground, smoking. The narrow stairs are covered with cigarette butts and broken glass. Two young men argue at the foot of the stairs. I'm nervous for a moment, but they leave. It's not clear why they were there.

We stoop to enter the windowless kitchen, where a four-month-old girl

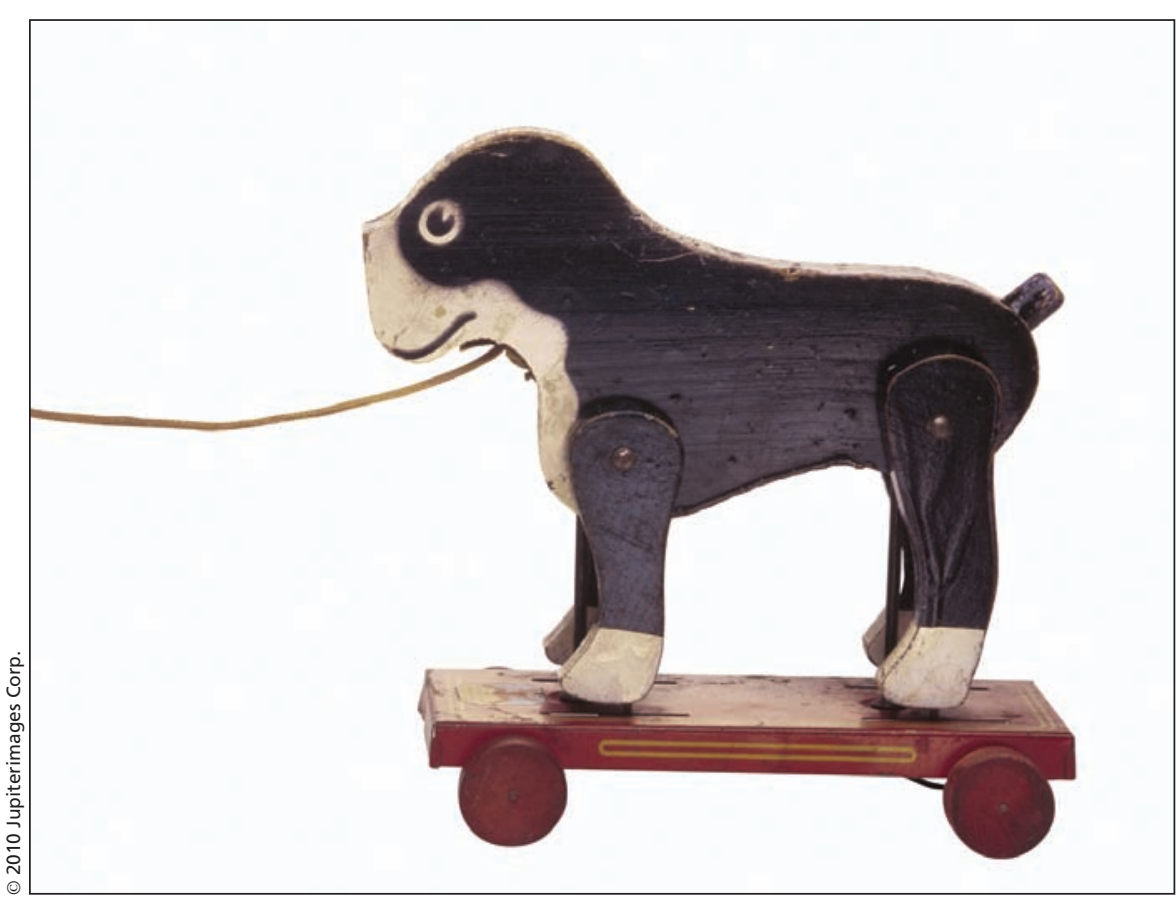

A support worker in Toronto, Ontario, lent a toy to a child who did not have one, but stressed that it was only on loan for one week.

sleeps. A naked light bulb hangs from the ceiling. The fridge is empty. There are a few cans of formula in the cupboard. The woman's boyfriend knocks over the fan and the cover comes off, leaving the blade spinning around on the floor. He doesn't pick it up.

When the stove is turned on, the room fills with steam and smoke.

I leave fearing for the physical safety of this family.

\section{The new Canadian}

The young woman does not talk about why she left the nation of her birth 18 months ago. At first, she stayed with an acquaintance but was exploited. She moved on to a series of shelters with her daughter but now has her first apartment. It is safe, large and clean.

In it, there is a photo of her boyfriend, who was deported, but no other possessions, nothing decorative. Her daughter is healthy and happy, exploring my handbag, identification badge and pen. The support worker lends her a toy, telling her that it must be returned after a week. It is the child's only toy.

\section{Home visits}

After returning from the visits, I brush up on my reading about the impact that housing has children's health.

The physical hazards of the homes I visited were obvious. Equally apparent were the limited play opportunities, whether because of location, design or lack of amenities. The experts say that is detrimental to brain development but in the homes I have visited, exploratory floor play is not advisable or even possible. These are children who have no exposure to books or building blocks.

Children living in crowded, noisy and chaotic environments demonstrate 
greater symptoms of psychological stress, perhaps due to stimulus overload.

Housing generally reflects family income. It seems that in low-income households, there may be a trade-off between spending on housing and spending on other health-enhancing commodities such as food. The experts also say the attributes of the neighbourhood, such as inclusion or the degree of socioeconomic and ethnic integration play a major role.

Housing clearly influences the incidence of our patients' diseases and our patient management. It is also often a factor in Children's Aid Society decisions to place a child in care. Yet, we rarely have insight into this factor, seeing the child only in the office or hospital.
It has been many years since the days of regular home visits and house calls. Most residents will never have the opportunity during their training to see a patient's home. It seems to me that should be revisited, so that all pediatric residents experience a home visit. Zoe Nugent MD, Toronto, Ont.

DOI:10.1503/cmaj.109-3668 